\title{
Numerical Study of Convection and Radiation Heat Transfer in Pipe Cable
}

\author{
Chen-Zhao Fu, ${ }^{1}$ Wen-Rong Si $\mathbb{D}^{1},{ }^{1}$ Lei Quan, ${ }^{2}$ and Jian Yang $\mathbb{D}^{2}$ \\ ${ }^{1}$ State Grid Shanghai Electrical Power Research Institute, Shanghai, 200437, China \\ ${ }^{2}$ Key Laboratory of Thermo-Fliud Science and Engineering, Xian Jiaotong University, Xian 710049, China \\ Correspondence should be addressed to Jian Yang; yangjian81@mail.xjtu.edu.cn
}

Received 30 June 2018; Accepted 28 August 2018; Published 17 September 2018

Academic Editor: Evangelos J. Sapountzakis

Copyright (c) 2018 Chen-Zhao Fu et al. This is an open access article distributed under the Creative Commons Attribution License, which permits unrestricted use, distribution, and reproduction in any medium, provided the original work is properly cited.

\begin{abstract}
Pipe cable is considered as an important form for underground transmission line. The maximum electrical current (ampacity) of power cable system mostly depends on the cable conductor temperature. Therefore, accurate calculation of temperature distribution in the power cable system is quite important to extract the cable ampacity. In the present paper, the fluid flow and heat transfer characteristics in the pipe cable with alternating current were numerically studied by using commercial code COMSOL MULTIPHYSICS based on finite element method (FEM). The cable core loss and eddy current loss in the cable were coupled for the heat transfer simulation, and the difference of heat transfer performances with pure natural convection model and radiationconvection model was compared and analysed in detail. Meanwhile, for the radiation-convection model, the effects caused by radiant emissivity of cable surface and pipe inner surface, as well as the cable location in the pipe, were also discussed. Firstly, it is revealed that the radiation and natural convection heat flux on the cable surface would be of the same order of magnitude, and the radiation heat transfer on the cable surface should not be ignored. Otherwise, the cable ampacity would be underestimated. Secondly, it is found that the overall heat transfer rate on the cable surface increases as the cable surface emissivity increases, and this is more remarkable to the upper cable. While the effect caused by the radiant emissivity on the pipe inner surface would be relatively small. Furthermore, it is demonstrated that, as cable location in the pipe falls, the natural convection heat transfer would be enhanced. These results would be meaningful for the ampacity prediction and optimum design for the pipe cable.
\end{abstract}

\section{Introduction}

As global economics increase, the demand for electricity supply increases rapidly [1]. The underground power cable is considered as one of the most common way to transmit the electrical power in the city $[2,3]$. For electric power transmission, cable ampacity is quite important for the cable safe operation, which is defined as the maximum cable current. The cable ampacity is usually limited by the cable temperature. When the maximum cable temperature is higher than $90^{\circ} \mathrm{C}$, the cable working life would be greatly shortened [4]. Therefore, it is important to predict the cable temperature precisely to ensure cable work safely and efficiently.

The underground power cable can be divided into directly buried cable and pipe-type cable. The directly buried cable is buried in the soil directly, and the heat is mainly transferred with heat conduction. While the pipe-type cable can be further divided into pipe cable, trench cable, and tunnel cable, and the heat can be transferred with heat conduction, natural convection, and thermal radiation. The traditional method for calculating underground cable ampacity (IEC standard $[5,6])$ is usually based on the basic heat transfer theory or empirical experimental correlations. As for heat transfer in pipe-type cables, the traditional calculation method with IEC standard would lead to some deviations due to its intrinsic deficiencies, where more empirical model constants were needed [7] and the boundary conditions were oversimplified [8]. With development of computer technology, the numerical simulation method has been widely used to predict the temperature and ampacity for underground power cables, especially for directly buried cables. For example, Ocłoń et al. [9] had numerically studied the heat transfer characteristics in directly buried cables with multilayer soil, where the 
variation of soil thermal conductivity was considered for the simulations. It was found that the effect of soil thermal conductivity on the heat transfer was quite remarkable for buried cables. Then, in their subsequent study (Ocłon et al. [10]), the particle swarm optimization method (PSO) was adopted to optimize the cable cross-sections, and the optimum dimensions were obtained. Rerak and Ocłon [11] had studied the heat transfer characteristics of directly buried cables with finite element method (FEM), where the effect of temperature-dependent thermal conductivities of soil and backfill material was considered. Naskar et al. [12] had developed a transient computational code with FEM for threecore cable, which could predict the transient temperature distribution in the cable quickly and accurately. In addition, in the study of Al-Saud [13], the FEM-PSO method was used to optimize the three-core cable cross-sections, and the optimum dimensions were obtained. Rasoulpoor et al. [14] had studied the heat transfer characteristics for buried cables with unbalanced current by using FEM method. In their study, the heat source produced by the cable was coupled and it was found that the cables arranged in parallel form would have longer working life. The above numerical researches were mainly focused on the heat transfer characteristics for the directly buried cables. As for pipe-type cables, the heat transfer inside is more complicated, and the numerical studies are relatively few. Liang et al. [8] had numerically studied the overall heat transfer performance for pipe cables, where the heat conduction, natural convection, and thermal radiation were considered in the simulations. However, in this study, each heat transfer effect was not analysed and compared separately. Liu et al. [15] had numerically studied the heat transfer performance for trench cables with different Rayleigh numbers. The local Nusselt number in the trench was analysed and it was found that the heat dissipation rate was closely related to the cable arrangement. Then, the heat transfer characteristics for trefoil cables exposed in the air were numerically studied by Liu et al. [16], where the thermal radiations between different cables were considered. It was found that the thermal radiations would have significant effect on the cable temperature and air velocity distributions. While, in this study, the eddy current loss in the cable caused by the alternating current was not considered, and the effect of cable locations was also not discussed. Furthermore, Boukrouche et al. [17] had numerically and experimentally studied the forced convection heat transfer for tunnel cables, where the effect caused by the distance between cable and tunnel wall under turbulence condition was mainly discussed. It was found that when the cable was close to tunnel wall, the radiation heat transfer would be enhanced and the convection heat transfer would be reduced. However, in this study, the natural convection in the tunnel was not discussed.

Based on the above literature survey, it shows that many researchers have studied heat transfer performances for underground cables, especially for directly buried cables. However, until recently, the related researches for the pipetype cables were still relatively few and each effect caused by the convection and radiation heat transfer on the heat dissipation for cables were still unclear. Therefore, in the present study, the fluid flow and heat transfer characteristics in the typical pipe cables were numerically investigated, where the cable core loss and eddy current loss in the cable were coupled for the heat transfer simulations. Meanwhile, the difference of heat transfer performances with pure natural convection model and radiation-convection model were compared and analysed in detail. For the radiation-convection model, the effects caused by radiant emissivity of cable surface and pipe inner surface, as well as the cable location in the pipe, were also discussed. The present research would be meaningful for the ampacity prediction and optimum design for the pipe cable.

\section{Physical Model and Computational Method}

2.1. Physical Model and Geometric Parameters. In the present study, the length of the cable is much longer than its diameter. Therefore, the heat transfer in the pipe cable would be simplified as two-dimensional heat transfer model $[18,19]$. The physical model of pipe cable and cable structure are presented in Figure 1. In Figure 1(a), it shows that the pipe cable consists of a PVC pipe and three single-core power cables, and the PVC pipe is full of air. In Figure 1(b), it shows that the power cable consists of cable core, insulation layer, sheath layer, and external layer. The typical geometric and physical parameters of the pipe cable are listed in Tables 1 and 2. When the cable is in work, the heat of Joule loss produced in cable core and eddy current loss produced in sheath layer is transferred to the cable surface through heat conduction. Then, the heat is taken away from the cable surface through natural convection and thermal radiation. For thermal radiation, the air in the pipe is regarded as a transmission medium, and both of the cable surface and pipe inner surface are regarded as diffuse-grey surfaces.

2.2. Governing Equations and Computational Method. In the present study, the pipe cable is divided into solid region (cables and PVC pipe) and fluid region (air flow in the PVC pipe). Then, the heat transfer in the solid and fluid regions is coupled for the simulations. As for the solid regions, the heat transfer can be considered as steady heat conduction, and the governing equations are as follows:

$$
\begin{aligned}
& \lambda \cdot \nabla^{2} T \\
& = \begin{cases}-q_{\mathrm{v}}, & \text { Cable core and sheath layer } \\
0, & \text { Insulation layer, external layer and PVC pipe }\end{cases}
\end{aligned}
$$

where $\lambda$ is the thermal conductivity of solid material. $q_{\mathrm{v}}$ is the heat loss of the cable, which is defined as follows:

$$
q_{\mathrm{v}}=\frac{|\vec{J}|^{2}}{\sigma_{1}}
$$

where $\sigma_{1}$ and $\vec{J}$ are the electronic conductivity and total current density in the cable, respectively. The total current 


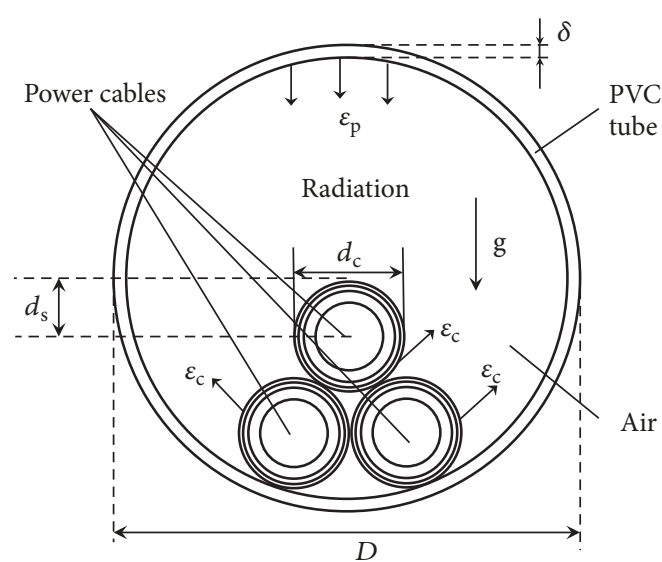

(a)

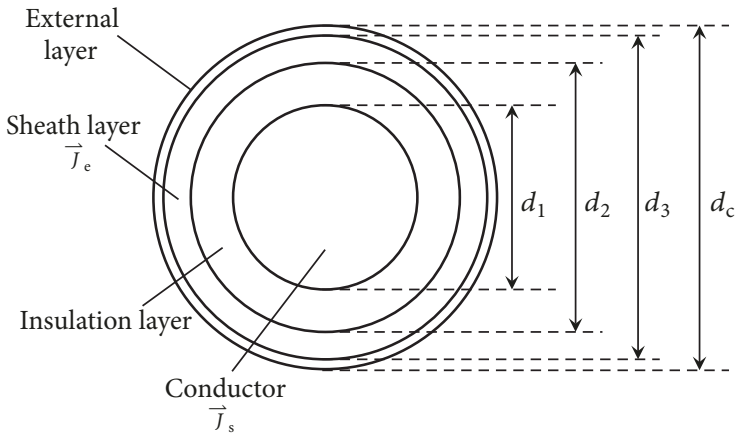

(b)

Figure 1: Physical model of pipe cable and cable structure. (a) Physical model of pipe cable. (b) Cable structure.

TABLE 1: Typical geometric parameters for pipe cable.

\begin{tabular}{lcccccc}
\hline$D[\mathrm{~mm}]$ & $\delta[\mathrm{mm}]$ & $d_{\mathrm{c}}[\mathrm{mm}]$ & $d_{1}[\mathrm{~mm}]$ & $d_{2}[\mathrm{~mm}]$ & $d_{3}[\mathrm{~mm}]$ & 140 \\
\hline 620 & 10 & 150 & 60.4 & 120 & $d_{\mathrm{s}}[\mathrm{mm}]$ \\
\hline
\end{tabular}

TABLE 2: Typical physical parameters for pipe cable.

\begin{tabular}{lcccc}
\hline Pipe cable & Material & $\begin{array}{c}\text { Thermal conductivity } \\
{[\mathrm{W} /(\mathrm{m} \cdot \mathrm{K})]}\end{array}$ & $\begin{array}{c}\text { Electronic } \\
\text { conductivity }[\mathrm{S} / \mathrm{m}]\end{array}$ & $\begin{array}{c}\text { Relative dielectric } \\
\text { constant }\end{array}$ \\
\hline Cable core & Copper & 400 & $5.998 \times 10^{7}$ & 1.0 \\
Insulation layer & XLPE & 0.286 & $1.0 \times 10^{-15}$ & 2.5 \\
Sheath layer & Aluminium & 238 & $3.774 \times 10^{7}$ & 1.0 \\
External layer & Polyethylene & 0.280 & $1.0 \times 10^{-15}$ & 2.5 \\
\hline PVC pipe & PVC & 0.167 & $1.0 \times 10^{-16}$ & 1.0 \\
\hline
\end{tabular}

density consists of source current density $\vec{J}_{\mathrm{s}}$ and eddy current $\vec{J}_{\mathrm{e}}$, which are defined as follows:

$$
\vec{J}
$$

$$
\begin{aligned}
& =\vec{J}_{\mathrm{e}} \\
& +\vec{J}_{\mathrm{s}} \begin{cases}\vec{J}_{\mathrm{s}}>0 & \left(\vec{J}_{\mathrm{s}}=-\sigma_{1} \nabla \varphi\right) \text {, Cable core } \\
\vec{J}_{\mathrm{e}}=0 & \left(\vec{J}_{\mathrm{e}}=-j \omega \sigma_{1} \vec{A}\right), \text { Sheath layer }\end{cases}
\end{aligned}
$$

where $\vec{A}, j, \omega$, and $\varphi$ are the magnetic vector potential, unit of complex number, angular frequency, and electric scalar potential, respectively.

As for the fluid region, the air flow can be considered as the steady laminar natural convection inside, and the governing equations for the mass, momentum, and energy are as follows:

Continuity is

$$
\nabla \cdot \vec{v}=0
$$

Momentum is

$$
\vec{v} \cdot \nabla \vec{v}=-\frac{1}{\rho_{\mathrm{f}}} \nabla p+v_{\mathrm{f}} \nabla^{2} \vec{v}+\beta\left(T-T_{0}\right) g
$$

where $\vec{v}$ is the velocity vector. $\rho_{\mathrm{f}}$ is the air density. $v_{\mathrm{f}}$ is the kinetic viscosity of air. $\beta$ is the volumetric expansion coefficient of air.

Energy is

$$
\rho_{\mathrm{f}} \mathcal{c}_{\mathrm{p}}(\vec{v} \cdot \nabla T)=\lambda_{\mathrm{f}} \cdot \nabla^{2} T
$$

where $\lambda_{\mathrm{f}}$ is the thermal conductivity of air. $c_{\mathrm{p}}$ is the specific heat at constant pressure of air.

The boundary conditions are set as follows:

$$
\begin{gathered}
-\lambda_{1} \frac{\partial T}{\partial r}=h_{1}\left(T-T_{\infty}\right) \quad \text { PVC pipe out surface } \\
\lambda_{1} \frac{\partial T}{\partial r}=h_{2}\left(T-T_{\mathrm{f}}\right)+\frac{\sigma_{2} T^{4}-J}{\left(1-\varepsilon_{\mathrm{p}}\right) / \varepsilon_{\mathrm{p}}}, \\
u=v=0 \text { PVC pipe inner surface } \\
-\lambda_{2} \frac{\partial T}{\partial r}=h_{3}\left(T-T_{\mathrm{f}}\right)+\frac{\sigma_{2} T^{4}-J}{\left(1-\varepsilon_{\mathrm{c}}\right) / \varepsilon_{\mathrm{c}}}, \\
u=v=0 \text { Cable surface }
\end{gathered}
$$

where $\lambda_{1}$ and $\lambda_{2}$ are the thermal conductivities of PVC pipe and cable external layer, respectively. $h_{1}$ is the equivalent heat 


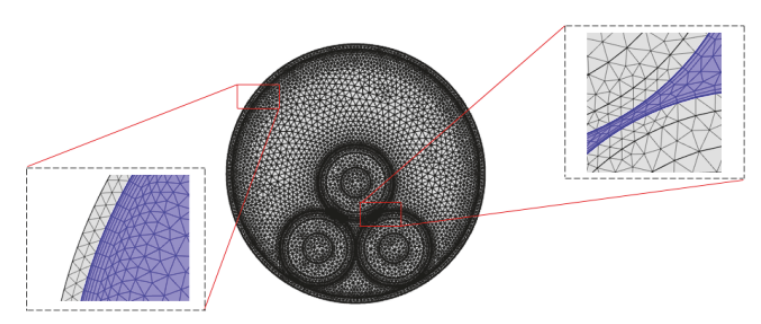

FIgURE 2: Computational mesh and contact model for pipe cable.

transfer coefficient on the PVC pipe out surface, which is set as $5 \mathrm{~W} /\left(\mathrm{m}^{2} \cdot \mathrm{K}\right) . h_{2}$ and $h_{3}$ are the convective heat transfer coefficients on PVC pipe inner surface and cable surface, respectively. $T_{\infty}$ represents the soil temperature, which is fixed at $293 \mathrm{~K}$. $T_{\mathrm{f}}$ is the air temperature in pipe. $\varepsilon_{\mathrm{p}}$ and $\varepsilon_{\mathrm{c}}$ are the radiant emissivity on the PVC inner surface and cable surface. $\sigma_{2}$ is the blackbody radiation constant. $J$ is the effective radiation.

In the present study, the governing equations are solved with commercial code COMSOL MULTIPHYSICS, and the Pardiso solver is employed for the computations. The conservative interface flux conditions for mass, momentum, and heat transfer are adopted at the solid-solid and solidfluid interfaces. For convergence criteria, all residuals of the calculations are less than $10^{-3}$.

\section{Grid Independence Test and Model Validations}

Firstly, the grid independence test was performed. As presented in Figure 2, the self-adaptive tetrahedral mesh was used for the computations. The grids are intensified on the interface between solid and fluid regions. In order to improve the mesh quality near the contact points between cable surfaces or between cable surfaces and pipe inner surface, according to the report of $\mathrm{Bu}$ et al. [20], the cables were stacked with very small gaps $\left(1.3 \% d_{\mathrm{c}}\right)$ instead of contact points between each other. In the present work, four sets of grids were used for the test, where the cable core current is equal to $1500 \mathrm{~A}$, and the total elements are 9294, 12046, 15762 , and 23670, respectively. The test results are presented in Figure 3. It shows that the grid with total element number of 15762 is good enough for the test, where the maximum length of the grid element is $8.1 \mathrm{~mm}$ and $0.01 \mathrm{~mm}$ for the main flow and near wall regions, respectively. The deviation of maximum cable temperature $\left(T_{\max }\right)$ between grids with total element number of 15762 and 23670 is less than $1 \%$. Therefore, similar grid settings to the test grid with total grid number of 15762 were employed for the following simulations.

Subsequently, the computational model and methods were validated. Since the heat transfer simulations for threephase pipe cable is relatively few, in the present study, the model validations for the heat conduction in the cable under electromagnetic field were performed first. The heat conduction in three-phase directly buried cable was validated, and

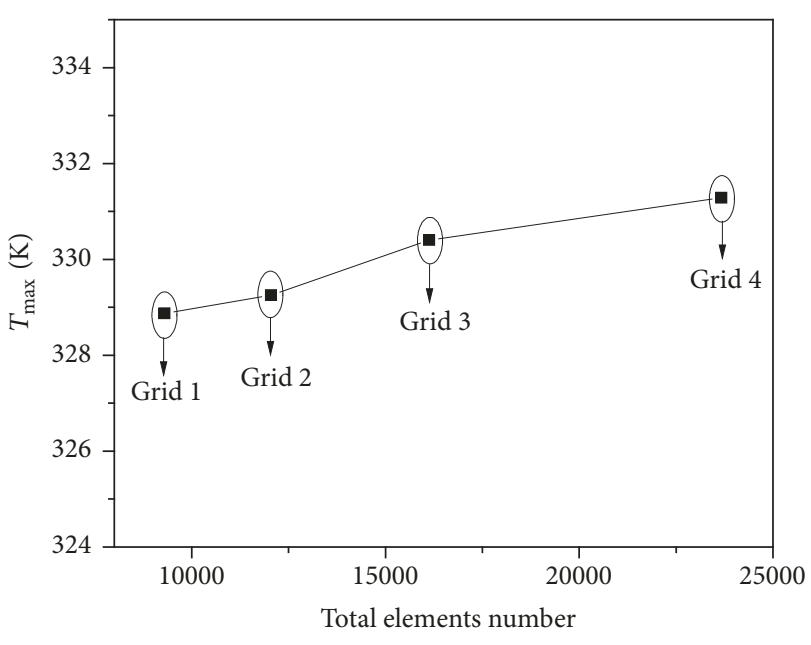

FIGURE 3: Grid independence test.

results were compared with those as reported by Dai et al. [21] and $\mathrm{Hu}$ [22] and calculated with IEC-60287 method. The physical model for the validation is presented in Figure 4. It shows that three-phase cables were parallel buried in the soil with distance of $0.2 \mathrm{~m}$ from each other. The distance from cable centre to the ground is $1 \mathrm{~m}$. The convection heat transfer coefficient on the ground surface is $14.74 \mathrm{~W} /\left(\mathrm{m}^{2} \cdot \mathrm{K}\right)$, and the air temperature is kept at $281 \mathrm{~K}$. Furthermore, the soil far away from the left and right sides of the cables is considered to be adiabatic, and the temperature of the soil far away from the bottom of the cables is set as $281 \mathrm{~K}$. Typical cable geometric and physical parameters for the validation are listed in Table 3, and the thermal conductivity of soil is set as $1 \mathrm{~W} /(\mathrm{m} \cdot \mathrm{K})$. The computational results are presented in Figure 5. It shows that the maximum temperature of threephase cable can agree well with those reported by Dai et al. [21] and $\mathrm{Hu}$ [22] and calculated with IEC method, where the maximum deviation of $T_{\max }$ is less than $4 \%$. Therefore, the present computational model and methods would be reliable for the simulation of heat conduction in the cable under electromagnetic field.

Then, the natural convection heat transfer together with thermal radiation in a square cavity was validated and the results were compared with those as reported by Ridouane et al. [23]. The physical model for the validation is presented in Figure 6. It shows that the bottom wall of the cavity is the hot wall and the temperature is fixed at $298.5 \mathrm{~K}$. The top wall of the cavity is the cold wall and the temperature is fixed at $288.5 \mathrm{~K}$. Two side walls are set as adiabatic and all the cavity walls are regarded as diffuse-grey surfaces. The computational results are presented in Table 4. It shows that the Nusselt numbers for the natural convection, thermal radiation, and total heat transfer on the top wall can agree well with those of Ridouane et al. [23]. The maximum deviation is $13.05 \%$, and most of the deviations are less than $4 \%$. Therefore, the present computational model and methods would be reliable for the simulation of natural convection heat transfer in a cavity coupled with thermal radiations. 


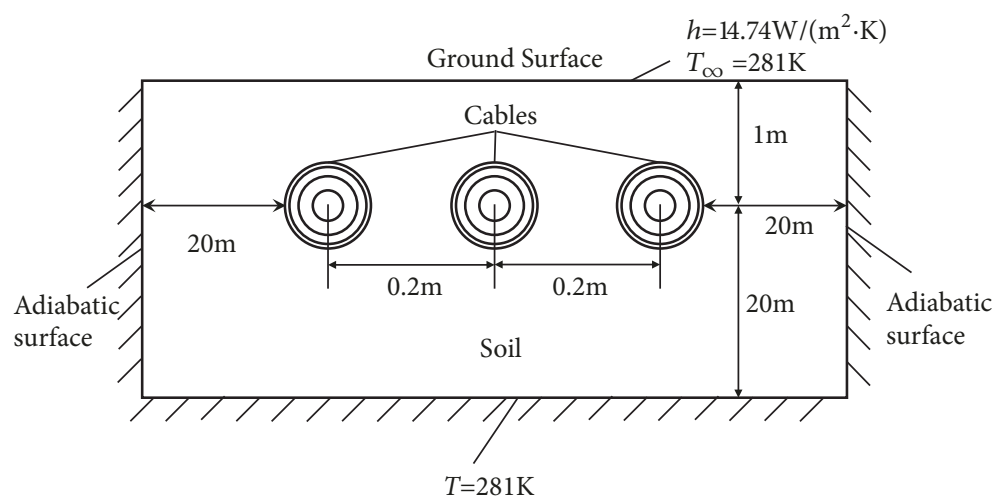

Figure 4: The geometric parameters for validation model (Dai et al. [21], Hu [22]).

TABle 3: Physical parameters for validation model (Dai et al. [21], Hu [22]).

\begin{tabular}{lccc}
\hline $\begin{array}{l}\text { Geometric dimensions }[\mathrm{mm}] \\
\text { Radius of cable }\end{array}$ & 15.1 & $\begin{array}{c}\text { Thermal } \\
\text { conductivity } \\
{[\mathrm{W} /(\mathrm{m} \cdot \mathrm{K})]}\end{array}$ & $\begin{array}{c}\text { Electronic } \\
\text { conductivity } \\
{[\mathrm{S} / \mathrm{m}]}\end{array}$ \\
$\begin{array}{l}\text { Rore } \\
\text { insulating layer }\end{array}$ & 22.4 & 400 & $5.998 \times 10^{7}$ \\
$\begin{array}{l}\text { Thickness of sheath } \\
\text { layer }\end{array}$ & 2.0 & 0.286 & $1.0 \times 10^{-15}$ \\
$\begin{array}{l}\text { Thickness of } \\
\text { external layer }\end{array}$ & 5.5 & 160 & $3.774 \times 10^{7}$ \\
\hline
\end{tabular}

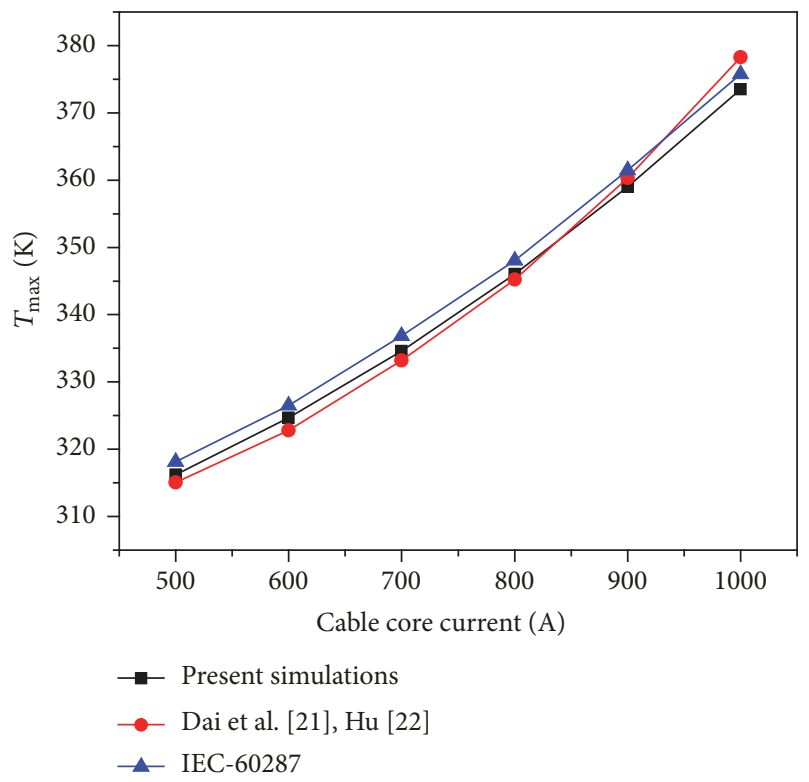

FIgURE 5: Computational results for model validation.

\section{Results and Discussion}

4.1. The Electromagnetic Loss in the Pipe Cable. Firstly, the electromagnetic loss in the cable with alternating current is analysed. In the present study, the imbalance effect caused

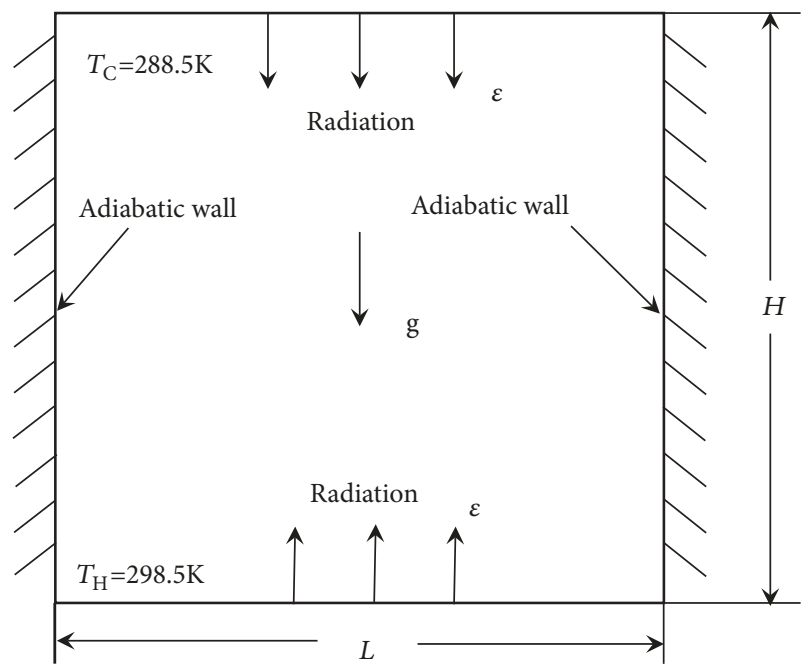

FIgure 6: The physical model for validation in Ridouane et al. [23].

by three-phase currents was not considered $[4,9,19]$, and the current is kept the same for each cable. The current distribution in the cable is presented in Figure 7. It shows that when alternating current is applied to the cable, the induced current would be produced in the cable core due to the variation of magnetic field surround the conductor, which would lead to inhomogeneous current distribution in the cable core cross-section and the skin effect appears. Due 
TABLE 4: The comparison of results between present study and Ridouane et al. [23].

\begin{tabular}{|c|c|c|c|c|c|}
\hline Results & $R a$ & $\varepsilon$ & $N u_{\text {conv }}$ & $N u_{\mathrm{rad}}$ & $N u_{\text {tot }}$ \\
\hline Ridouane et al. [23] & \multirow{3}{*}{$10^{6}$} & \multirow{3}{*}{0.5} & 6.267 & 6.599 & 12.866 \\
\hline Present simulation & & & 6.353 & 6.812 & 13.165 \\
\hline Deviation & & & $1.37 \%$ & $3.23 \%$ & $2.32 \%$ \\
\hline Ridouane et al. [23] & \multirow{3}{*}{$4 \times 10^{5}$} & \multirow{3}{*}{1.0} & 4.722 & 11.462 & 16.183 \\
\hline Present simulation & & & 5.338 & 11.883 & 16.800 \\
\hline Deviation & & & $13.05 \%$ & $3.67 \%$ & $3.81 \%$ \\
\hline
\end{tabular}

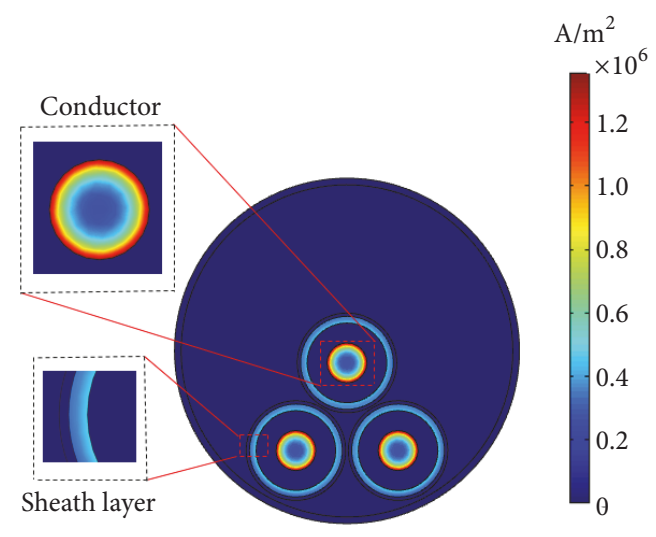

FIgURE 7: Current distributions in the cable core and sheath layer.

to the skin effect, the current would concentrate near the cable core surface, which would lead to the increase of cable resistance. Meanwhile, the induced current will form a closed loop in the sheath layer, and the eddy current loss would be produced inside.

The cable electromagnetic loss includes conductor loss produced in the cable core and the eddy current loss produced by induced current. The distribution and variations of electromagnetic loss in the cable are presented in Figure 8. From Figure 8(a), it shows that the heat loss in the cable core is inhomogeneous, which increases gradually along the radius direction and reaches maximum value at the cable core surface. This is consistent with the phenomenon of skin effect in the cable core. Meanwhile, in the sheath layer, the eddy current loss would be produced due to the inducted current. Furthermore, from Figure 8(b), it shows that both the cable core heat loss and eddy current loss increase as the cable core current increases and the eddy current loss is relatively small.

4.2. Heat Transfer Performance in the Pipe Cable with Different Simulation Models. In this section, the fluid flow, heat transfer, and cable ampacity in the pipe cable were analysed and compared for the pure natural convection model and radiation-convection model. The velocity and temperature distributions of pipe cable with and without thermal radiations are presented in Figure 9. It shows that the air velocity in the pipe simulated with the radiation-convection model is obviously lower than that simulated with the pure convection model. The maximum air velocity is near the lateral sides of the upper cable for both the simulation models. When the cable core current is equal to $1500 \mathrm{~A}$, the maximum air velocity is $0.21 \mathrm{~m} / \mathrm{s}$ and $0.27 \mathrm{~m} / \mathrm{s}$ for the radiation-convection model and pure convection model, respectively. This means the natural convection in the pipe simulated with the pure convection model would be higher than that simulated with the radiation-convection model. Furthermore, it also shows that the temperature in the pipe cable simulated with the radiation-convection model is lower than that simulated with the pure convection model. The maximum temperature in the pipe cable is located at the cable core of the upper cable for both simulation models. When the cable core current is equal to $1500 \mathrm{~A}$, the maximum temperature in the cable core is 315.9 $\mathrm{K}$ and $325.0 \mathrm{~K}$ for the radiation-convection model and pure convection model, respectively. This means the overall heat transfer rate in the pipe cable for the radiation-convection model would be higher than that for the pure convection model.

The variations of heat flux on the cable surfaces for the radiation-convection model are presented in Figure 10. It shows that the heat fluxes on the cable surfaces increase as cable core current increases. The radiation heat flux $\left(\Phi_{\mathrm{rad}}\right)$ and convection heat flux $\left(\Phi_{\text {conv }}\right)$ on the cable surface are of the same order of magnitude $\left(\Phi_{\mathrm{rad}}=18.4 \mathrm{~W}\right.$ and $\Phi_{\text {conv }}=42.8$ $\mathrm{W}$, when the cable core current equals to $1500 \mathrm{~A})$. Therefore, the radiation heat transfer on the cable surface should not be ignored.

The cable ampacity is the corresponding current in the cable core when the maximum cable core temperature reaches $90^{\circ} \mathrm{C}(363 \mathrm{~K})$. The variations of the maximum cable core temperature with and without thermal radiation are presented in Figure 11. It shows that, with the same cable core current, the maximum cable core temperature for the pure convection model is obviously higher than that for the radiation-convection model. This means, with the same operation condition, the overall heat transfer rate in the pipe cable would be underestimated, and the cable ampacity would also be underestimated. In the present study, the cable ampacity for the upper and lower cables using pure convection model are 2339.2 A and 2597.5 A, respectively, while the cable ampacity for the upper and lower cables using radiation-convection model are 2749.5 A and 2803.2 A, respectively. The deviations of cable ampacity using different models are $-14.9 \%$ and $-7.3 \%$ for the upper and lower cables, respectively. Therefore, when the cable ampacity of pipe cable is calculated, both the natural convection and radiation heat 


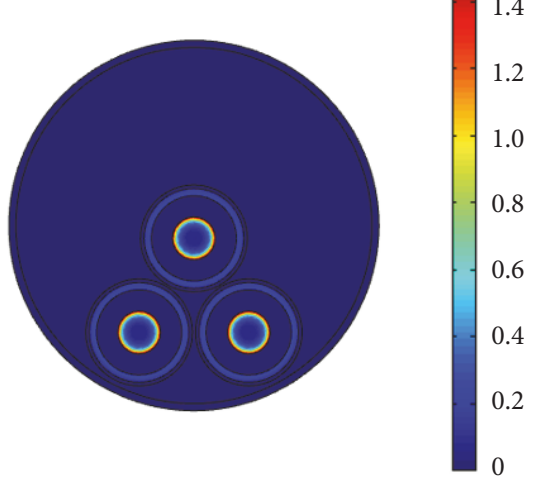

(a)

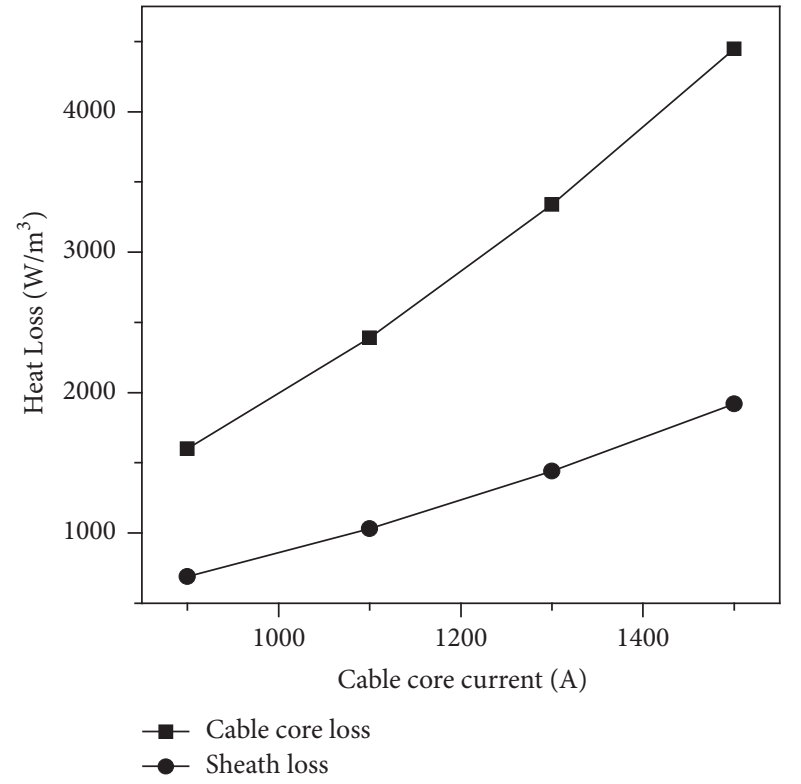

(b)

FIGURE 8: Distribution and variations of electromagnetic loss in the cable. (a) Distribution of electromagnetic loss (cable core current equals 1500 A). (b) Cable core loss and Sheath loss.
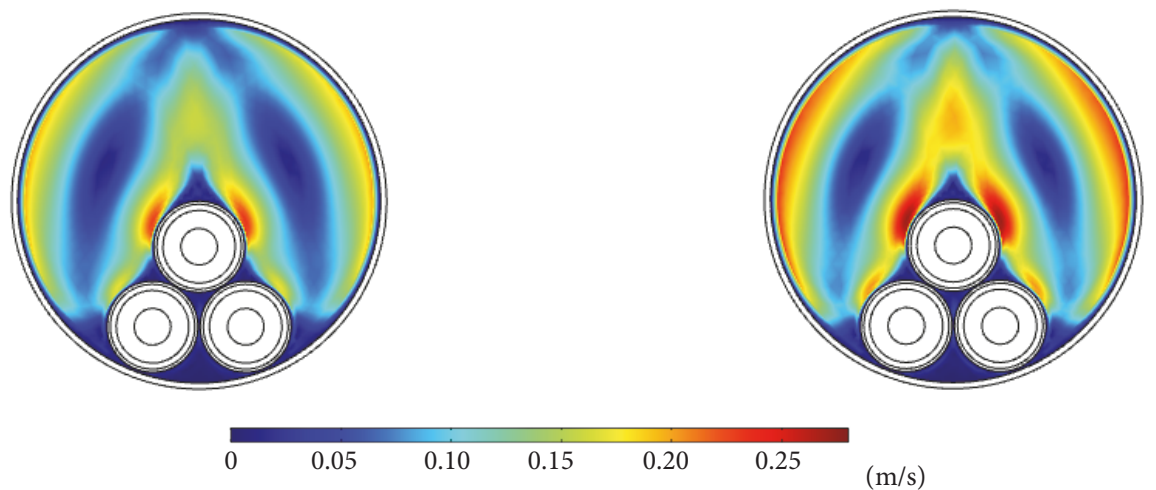

(a)
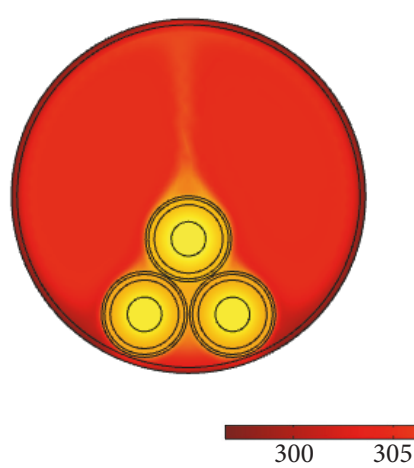

$(\mathrm{m} / \mathrm{s})$

(b)

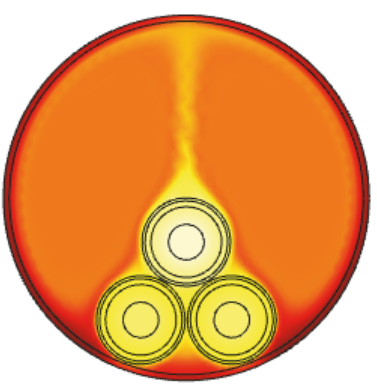

(K)

(c)

(d)

Figure 9: Velocity and temperature distributions of pipe cable with and without thermal radiations (cable core current equals 1500 A). (a) Velocity distribution (with radiation). (b) Velocity distribution (without radiation). (c) Temperature distribution (with radiation). (d) Temperature distribution (without radiation). 


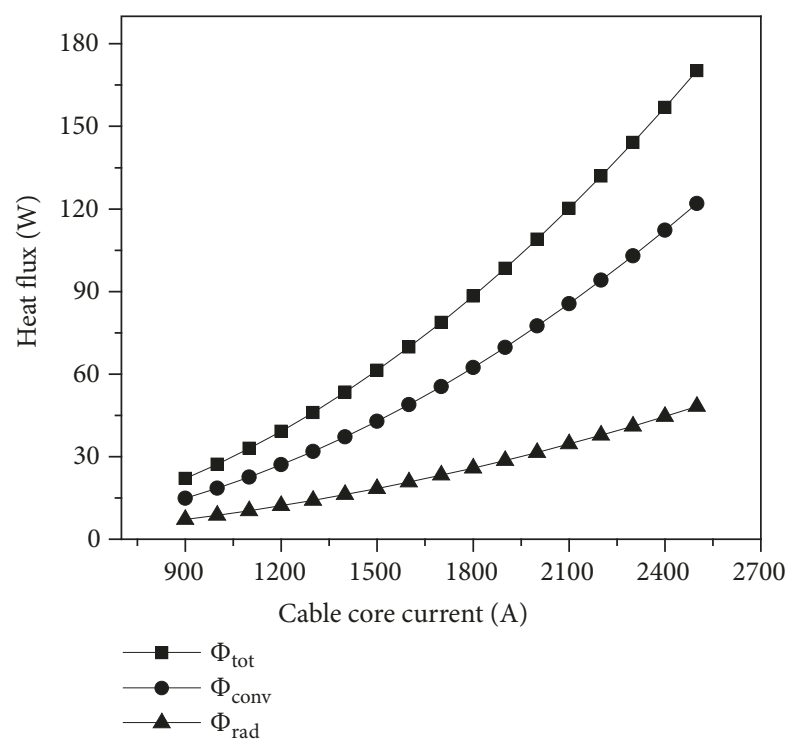

Figure 10: Variations of heat flux on the cable surfaces for the radiation-convection model.

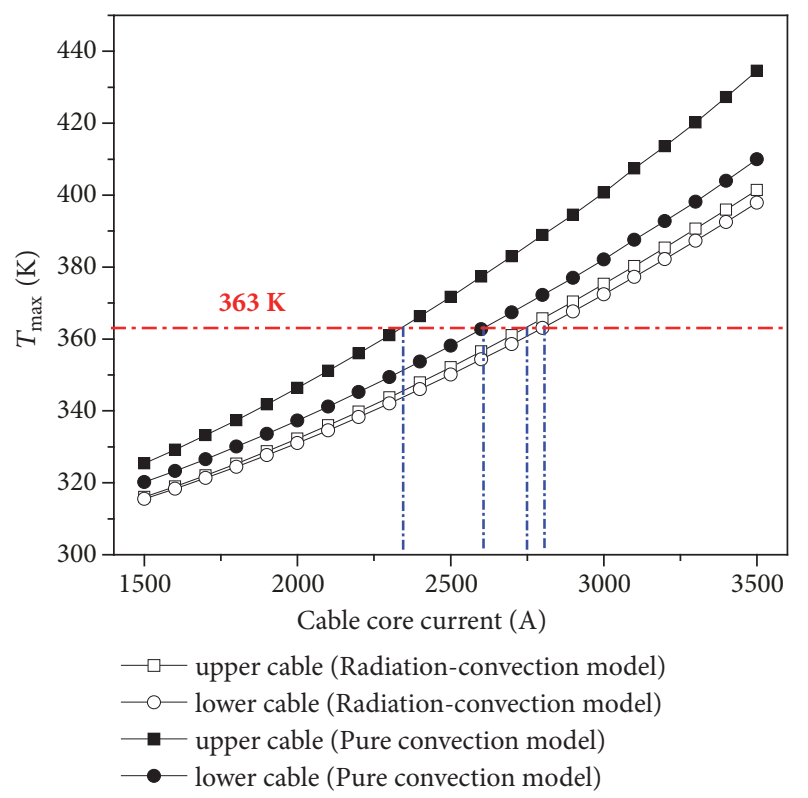

FIGURE 11: Variations of the maximum cable core temperature with and without thermal radiation.

transfer on the cable surfaces should be considered in the simulation model. Otherwise, the cable ampacity would be underestimated.

\subsection{The Effects of Surface Radiant Emissivity and Cable} Location. Based on above analysis, it shows that both the radiation and convection heat transfer on the cable surfaces are important in the pipe cable. Therefore, in this section, the effects caused by the radiant emissivity of cable surface $\left(\varepsilon_{c}\right)$ and pipe inner surface $\left(\varepsilon_{\mathrm{p}}\right)$, as well as the cable location in the pipe, were discussed for the radiation-convection model.
The variations of the maximum temperature in the cable core and heat flux on the cable surface with surface radiant emissivity are presented in Figure 12. From Figure 12(a), it is shown that, with the same radiant emissivity of pipe inner surface $\left(\varepsilon_{\mathrm{p}}\right)$, the maximum temperature $\left(T_{\max }\right)$ in the cable core decreases as the radiant emissivity of cable surface $\left(\varepsilon_{\mathrm{c}}\right)$ increases, and the effect of $\varepsilon_{\mathrm{c}}$ is more remarkable on the upper cable. This may indicate that the overall heat transfer rate would increase as $\varepsilon_{\mathrm{c}}$ increases, and the effect of $\varepsilon_{\mathrm{c}}$ on the overall heat transfer rate for the upper cable would be more remarkable. For the upper cable, the geometric resistance is relative small. Therefore, the effect of the surface radiant emissivity on the radiation heat transfer would be remarkable. Meanwhile, with the same $\varepsilon_{c}$, the variation of the maximum temperature in the cable core is insignificant as $\varepsilon_{\mathrm{p}}$ changes. In the present study, the inner surface area of the pipe is much larger than the cable surface, and the surface resistance on the inner surface of the pipe is relatively small. Therefore, the variation of radiation heat transfer in the pipe cable would be insignificant as $\varepsilon_{\mathrm{p}}$ changes. In addition, from Figure 12(b), it would be found that, as surface radiant emissivity increases, the radiation heat flux $\left(\Phi_{\text {rad }}\right)$ on the cable surfaces increases, while the natural convection heat flux $\left(\Phi_{\text {conv }}\right)$ decreases. Since the cable temperature decreases as the surface radiant emissivity increases, the air temperature difference in the pipe decreases and the natural convection heat flux on the cable surfaces decreases.

The velocity and temperature distributions in the pipe cable with different $d_{\mathrm{s}}$ are presented in Figure 13, where the cable location is controlled by $d_{\mathrm{s}}$ as shown in Figure 1(a). Here $d_{\mathrm{s}}$ is the vertical distance from the upper cable centre to the pipe centre. From Figure 13(a), it is shown that the air velocity in the pipe increases obviously as the cable location falls. When the cable current equals $1500 \mathrm{~A}$, the maximum air velocity in the pipe is $0.128 \mathrm{~m} / \mathrm{s}$ and $0.212 \mathrm{~m} / \mathrm{s}$ for the case of $d_{\mathrm{s}}=75 \mathrm{~mm}$ and $d_{\mathrm{s}}=-75 \mathrm{~mm}$, respectively. This may indicate that the natural convection in the pipe would be enhanced as the pipe location falls. Meanwhile, from Figure 13(b), it shows that the temperature difference in the cable core is relatively small with different $d_{s}$. When the cable core current equals $1500 \mathrm{~A}$, the maximum temperature is located in the cable core of the upper cable for different $d_{\mathrm{s}}$ models and the maximum cable core temperature is $317.0 \mathrm{~K}$ and $315.9 \mathrm{~K}$ for the case of $d_{\mathrm{s}}=75 \mathrm{~mm}$ and $d_{\mathrm{s}}=-75 \mathrm{~mm}$, respectively. As the cable location falls, the natural convection heat transfer in the pipe increases, while the radiation heat transfer decreases since the geometric resistance between the cable surfaces and the pipe inner surface increases. Therefore, as $d_{\mathrm{s}}$ changes, the overall heat transfer rate in the pipe cable remains almost unchanged. The variations of heat flux on the cable surfaces for different $d_{\mathrm{s}}$ are presented in Figure 14 . It is shown that the heat flux on the cable surface increases as the cable core current increases. The radiation heat flux $\left(\Phi_{\mathrm{rad}}\right)$ and convection heat flux $\left(\Phi_{\text {conv }}\right)$ on the cable surface are of the same order of magnitude $\left(\Phi_{\text {rad }}=18.4 \mathrm{~W}\right.$ and $\Phi_{\text {conv }}=42.8 \mathrm{~W}$ with $d_{\mathrm{s}}=-75 \mathrm{~mm}$, when the cable core current equals $1500 \mathrm{~A}$ ). Therefore, the radiation heat transfer on the cable surface should not be ignored. As the cable location falls, the natural convection heat flux on the cable 


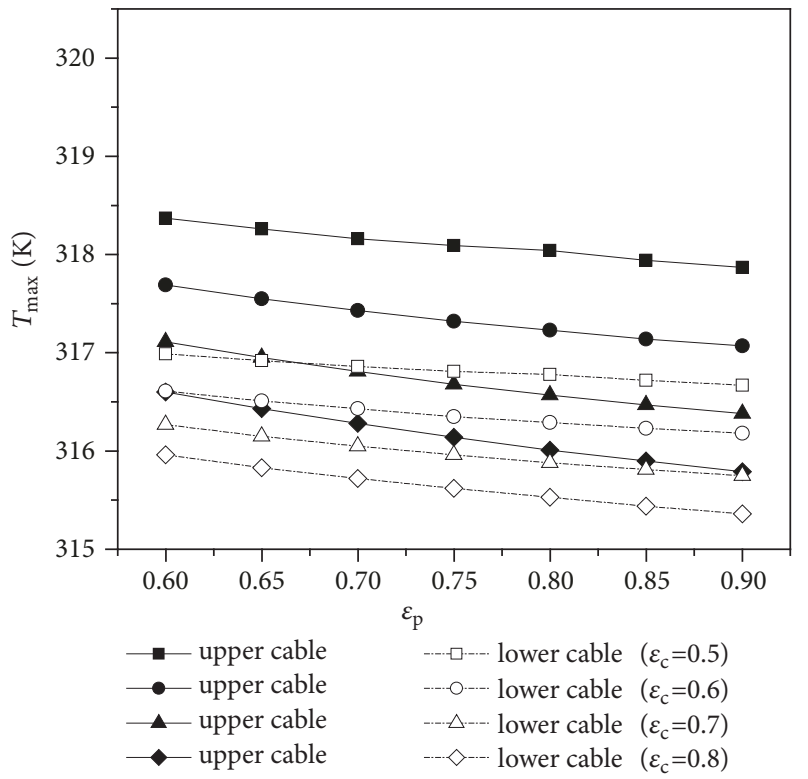

(a)

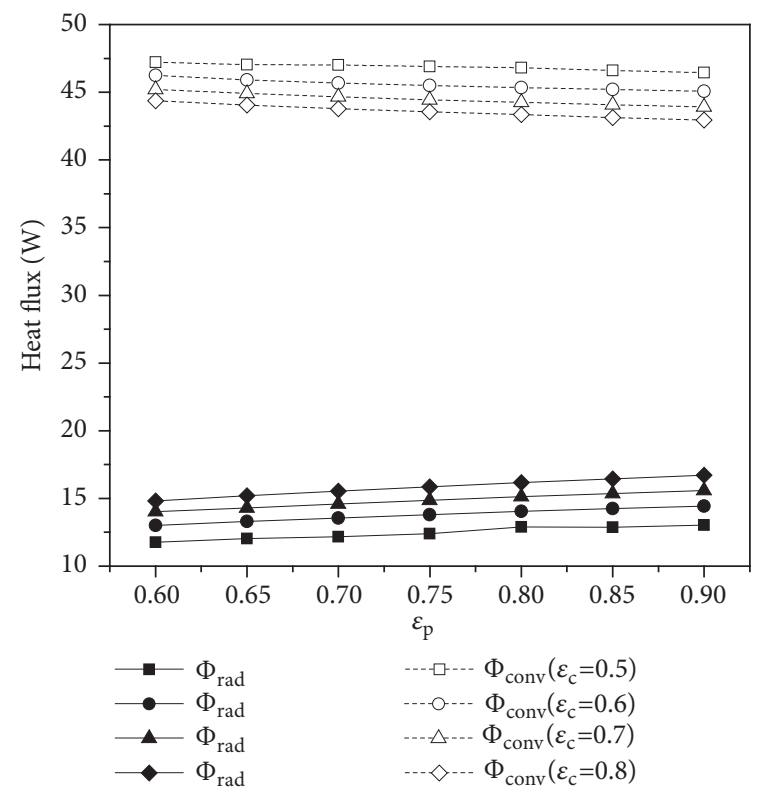

(b)

FIGURE 12: Variations of the maximum temperature in the cable core and heat flux on the cable surface with surface radiant emissivity (cable core current equals 1500 A). (a) Maximum temperature in the cable core. (b) Heat flux on the cable surface.

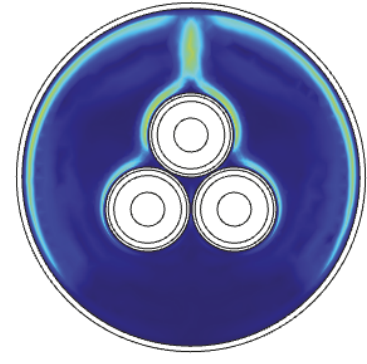

$d_{\mathrm{s}}=75 \mathrm{~mm}$

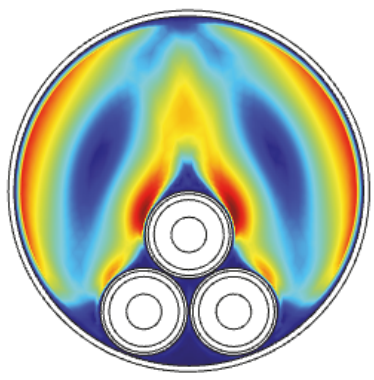

$d_{\mathrm{s}}=-75 \mathrm{~mm}$

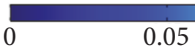

(a)
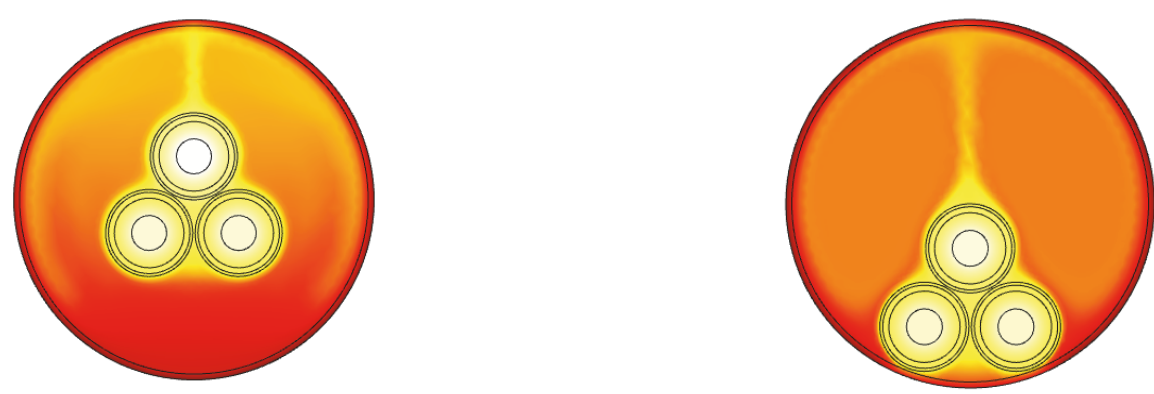

$$
d_{\mathrm{s}}=75 \mathrm{~mm} \quad d_{\mathrm{s}}=-75 \mathrm{~mm}
$$

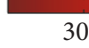

$300 \quad 305$

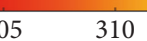

(b)

FIgURE 13: Velocity and temperature distributions in the pipe cable with different $d_{\text {s }}$ (cable core current equals 1500 A). (a) Velocity distributions. (b) Temperature distributions. 


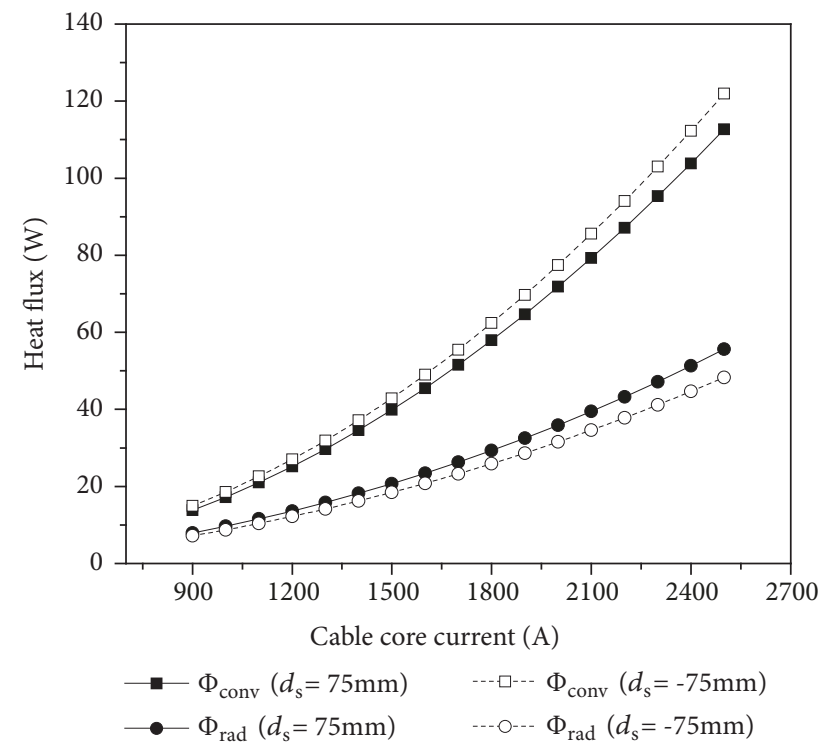

FIGURE 14: Variation of heat flux on the cable surfaces for different $d_{\text {s. }}$.

surfaces increases, while the radiation heat flux decreases, and the overall heat transfer rate in the pipe cable keeps almost unchanged.

\section{Conclusions}

In the present paper, the fluid flow and heat transfer characteristics in the typical pipe cables with alternating current were numerically investigated, where the cable core loss and eddy current loss in the cable were coupled for the heat transfer simulations. Meanwhile, the effects of convection and radiation heat transfer on the cable surface were analysed. For the radiation-convection model, the effects caused by surface radiant emissivity, as well as the cable location in the pipe, were also discussed. The main findings are as follows.

(1) The cable core loss and eddy current loss would exist simultaneously in the power cable with alternating current. The heat loss in the cable core is inhomogeneous, which increases gradually along the radius direction and it is consistent with the phenomenon of skin effect in the cable core. Both the cable core loss and eddy current loss increase as the cable core current increases and the eddy current loss is relatively small.

(2) The natural convection in the pipe simulated with the pure convection model would be higher than that simulated with the radiation-convection model, while the overall heat transfer efficiency in the pipe cable for the radiationconvection model would be higher than that for the pure convection model. The radiation heat flux and convection heat flux on the cable surface are of the same order of magnitude. Therefore, the radiation heat transfer on the cable surface should not be ignored. Otherwise, the cable ampacity would be underestimated.
(3) For the radiation-convection model, the overall heat transfer rate would increase as the radiant emissivity of cable surface $\left(\varepsilon_{\mathrm{c}}\right)$ increases. The effect of $\varepsilon_{\mathrm{c}}$ on the overall heat transfer rate for the upper cable would be more remarkable, while the effect of the radiant emissivity of pipe inner surface $\left(\varepsilon_{\mathrm{p}}\right)$ is relatively small. Furthermore, as the cable location falls, the natural convection heat flux on the cable surfaces increases, while the radiation heat flux decreases, and the overall heat transfer rate in the pipe cable remains almost unchanged.

\section{Nomenclature}

$\vec{A}: \quad$ Magnetic vector potential (Wb/m)

$c_{\mathrm{p}}$ : $\quad$ Specific heat at the constant pressure

$(\mathrm{J} /(\operatorname{kg~K}))$

D: $\quad$ Pipe diameter $(\mathrm{m})$

$d_{1}$ : $\quad$ Cable core diameter $(\mathrm{m})$

$d_{2}$ : Insulating layer diameter $(\mathrm{m})$

$d_{3}: \quad$ Sheath layer diameter $(\mathrm{m})$

$d_{\mathrm{c}}: \quad$ Cable diameter $(\mathrm{m})$

$d_{s}$ : $\quad$ Vertical distance from the upper cable centre to the tube centre $(\mathrm{m})$

g: Gravitational acceleration $\left(\mathrm{m} / \mathrm{s}^{2}\right)$

$h_{1}$ : Equivalent heat transfer coefficient on PVC pipe out surface $\left(\mathrm{W} /\left(\mathrm{m}^{2} \mathrm{~K}\right)\right)$

$h_{2}$ : Convective heat transfer coefficient on

PVC pipe inner surface $\left(\mathrm{W} /\left(\mathrm{m}^{2} \mathrm{~K}\right)\right)$

$h_{3}$ : Convective heat transfer coefficient on the

cable surface $\left(\mathrm{W} /\left(\mathrm{m}^{2} \mathrm{~K}\right)\right)$

$J: \quad$ Effective radiation $\left(\mathrm{W} / \mathrm{m}^{2}\right)$

$j: \quad$ Unit of complex number

$\mathrm{Nu}$ : Nusselt number

$N u_{\text {conv }}$ : Nusselt number for natural convection heat transfer

$N u_{\text {rad }}$ Equivalent Nusselt number for radiation heat transfer

$N u_{\text {tot }}: \quad$ Nusselt number for total heat transfer

$\mathrm{Ra}: \quad$ Rayleigh number

T: $\quad$ Temperature $(\mathrm{K})$

$T_{\mathrm{f}}$ : Temperature of air $(\mathrm{K})$

$T_{\infty}: \quad$ External temperature $(\mathrm{K})$

$\vec{v}: \quad$ Velocity $(\mathrm{m} / \mathrm{s})$

\section{Greek Letters}

$\beta$ : Volumetric expansion coefficient of air

$\delta$ : Thickness of PVC pipe (m)

$\varepsilon_{\mathrm{c}}$ : Radiant emissivity on cable surface

$\varepsilon_{\mathrm{p}}$ : Radiant emissivity on the inner surface of PVC pipe

$\Phi$ : Heat flux $(\mathrm{W})$

$\varphi$ : Electric scalar potential (V)

$\lambda$ : Thermal conductivity of solid material $(\mathrm{W} /(\mathrm{m} \mathrm{k}))$

$\lambda_{\mathrm{f}}$ : Thermal conductivity of air $(\mathrm{W} /(\mathrm{m} \mathrm{k}))$

$v_{\mathrm{f}}$ : Kinetic viscosity of air $\left(\mathrm{m}^{2} / \mathrm{s}\right)$

$\rho_{\mathrm{f}}$ : Density of air $\left(\mathrm{kg} / \mathrm{m}^{3}\right)$

$\sigma_{1}$ : Electronic conductivity $(\mathrm{S} / \mathrm{m})$

$\sigma_{2}$ : Blackbody radiation constant

$\omega$ : Angular frequency ( $\mathrm{rad} / \mathrm{s})$ 


\author{
Subscripts \\ $c$ : Cable \\ conv: Convection \\ $f: \quad$ Fuild \\ $p$ : $\quad$ Pipe \\ rad: Radiation \\ tot: Total
}

\section{Abbreviations}

PSO: Particle swarm optimization

PVC: Polyvinyl chloride

XLPE: Cross linked polyethylene.

\section{Data Availability}

The data used to support the findings of this study are included within the article.

\section{Conflicts of Interest}

The authors declare that there are no conflicts of interest regarding the publication of this paper.

\section{Acknowledgments}

This work was financially supported by the project Research and Demonstration Application of Temperature Rise Algorithm for Buried (Direct Buried and Pipe Laying) Cable Group from State Grid Corporation of China (SGCC) under Grant 52094018001K.

\section{References}

[1] J. M. Wang, J. Zhang, and J. Nie, "An Improved Artificial Colony Algorithm Model for Forecasting Chinese Electricity Consumption and Analyzing Effect Mechanism," Mathematical Problems in Engineering, vol. 2016, Article ID 8496971, 14 pages, 2016.

[2] E. Kroener, A. Vallati, and M. Bittelli, "Numerical simulation of coupled heat, liquid water and water vapor in soils for heat dissipation of underground electrical power cables," Applied Thermal Engineering, vol. 70, no. 1, pp. 510-523, 2014.

[3] P. Ocłoń, P. Cisek, M. Rerak et al., “Thermal performance optimization of the underground power cable system by using a modified Jaya algorithm," International Journal of Thermal Sciences, vol. 123, pp. 162-180, 2018.

[4] P. Ocłoń, P. Cisek, D. Taler, M. Pilarczyk, and T. Szwarc, "Optimizing of the underground power cable bedding using momentum-type particle swarm optimization method," Energy, vol. 92, pp. 230-239, 2015.

[5] IEC 60287-2-1: Electric cables-calculation of the current rating Part 2: Thermal resistance-Section 1: calculation of the thermal resistance, 1995.

[6] IEEE 835-1994: IEEE Standard Power Cable Ampacity Tables, 1994.

[7] G. J. Anders, M. Coates, and M. Chaaban, "Ampacity calculations for cables in shallow troughs," IEEE Transactions on Power Delivery, vol. 25, no. 4, pp. 2064-2072, 2010.
[8] Y.-C. Liang, Z.-J. Wang, J.-Y. Liu, Z.-H. Xue, and Y.-M. Li, "Numerical calculation of temperature field and ampacity of cables in ducts," Gaodianya Jishu/High Voltage Engineering, vol. 36, no. 3, pp. 763-768, 2010.

[9] P. Ocłoń, P. Cisek, M. Pilarczyk, and D. Taler, "Numerical simulation of heat dissipation processes in underground power cable system situated in thermal backfill and buried in a multilayered soil," Energy Conversion and Management, vol. 95, pp. 352-370, 2015.

[10] P. Ocłoń, M. Bittelli, P. Cisek et al., “The performance analysis of a new thermal backfill material for underground power cable system," Applied Thermal Engineering, vol. 108, pp. 233-250, 2016.

[11] M. Rerak and P. Ocłoń, "Thermal analysis of underground power cable system," Journal of Thermal Science, vol. 26, no. 5, pp. 465-471, 2017.

[12] A. K. Naskar, N. K. Bhattacharya, and D. Sarkar, "Transient thermal analysis of underground power cables using two dimensional finite element method," Microsystem Technologies, vol. 24, no. 2, pp. 1279-1293, 2018.

[13] M. S. Al-Saud, "Particle swarm optimization of power cable performance in complex surroundings," IET Generation Transmission and Distribution, vol. 12, no. 10, pp. 2452-2461, 2018.

[14] M. Rasoulpoor, M. Mirzaie, and S. M. Mirimani, "Electromagnetic and thermal analysis of underground power solidconductor cables under harmonic and unbalancing currents based on FEM," International Journal of Numerical Modelling: Electronic Networks, Devices and Fields, vol. 31, no. 1, 2018.

[15] Y. Liu, N. Phan-Thien, R. Kemp, and X.-L. Luo, "Coupled conduction-convection problem for an underground rectangular duct containing three insulated cables," Numerical Heat Transfer, Part A: Applications, vol. 31, no. 4, pp. 411-431, 1997.

[16] Y. Liu, N. Phan-Thien, R. Kemp, and X.-L. Luo, "A coupled conduction convection and radiation problem for three insulated cables suspended in air," Computational Mechanics, vol. 22, no. 4, pp. 326-336, 1998.

[17] F. Boukrouche, C. Moreau, J. Pelle, F. Beaubert, S. Harmand, and O. Moreau, "Mock-Up Study of the Effect of Wall Distance on the Thermal Rating of Power Cables in Ventilated Tunnels," IEEE Transactions on Power Delivery, vol. 32, no. 6, pp. 24532461, 2017.

[18] C.-C. Hwang and Y.-H. Jiang, "Extensions to the finite element method for thermal analysis of underground cable systems," Electric Power Systems Research, vol. 64, no. 2, pp. 159-164, 2003.

[19] Y.-C. Liang, J.-A. Chai, Y.-M. Li, Z.-G. Wang, and Z.-K. Li, "Calculation of eddy current losses in XLPE cables by FEM," Gaodianya Jishu/High Voltage Engineering, vol. 33, no. 9, pp. 196-199, 2007.

[20] S. S. Bu, J. Yang, M. Zhou, S. Y. Li, Q. W. Wang, and Z. X. Guo, "On contact point modifications for forced convective heat transfer analysis in a structured packed bed of spheres," Nuclear Engineering and Design, vol. 270, pp. 21-33, 2014.

[21] D. Dai, M. Hu, and L. Luo, "Calculation of thermal distribution and ampacity for underground power cable system by using electromagnetic-thermal coupled model," in Proceedings of the 32nd Electrical Insulation Conference, EIC 2014, pp. 303-306, USA, June 2014. 
[22] M. L. Hu, Calculation of thermal distribution and ampacity for high-voltage power cables by using multi-physics coupled model, South China University of Technology, Guangzhou, China, 2015.

[23] E. H. Ridouane, M. Hasnaoui, A. Amahmid, and A. Raji, "Interaction between natural convection and radiation in a square cavity heated from below," Numerical Heat Transfer, Part A: Applications, vol. 45, no. 3, pp. 289-311, 2004. 


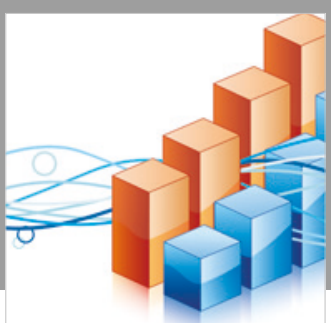

Advances in

Operations Research

\section{-n-m}
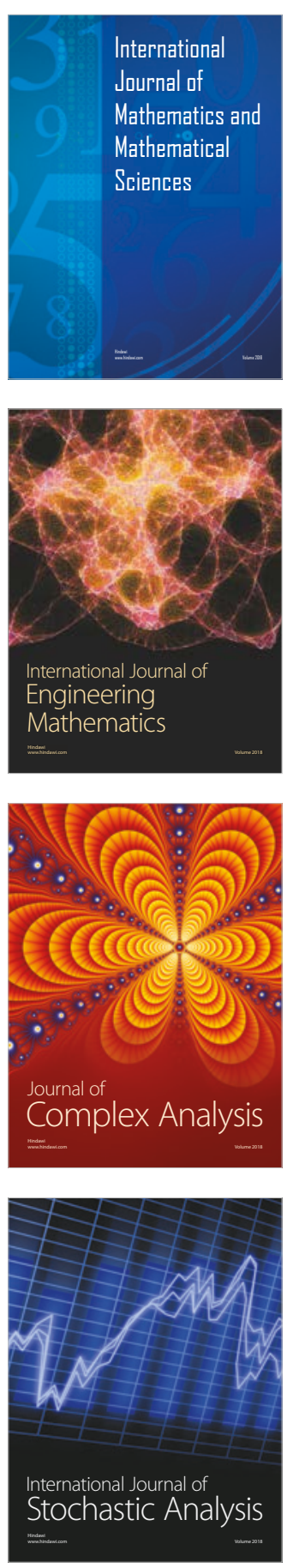
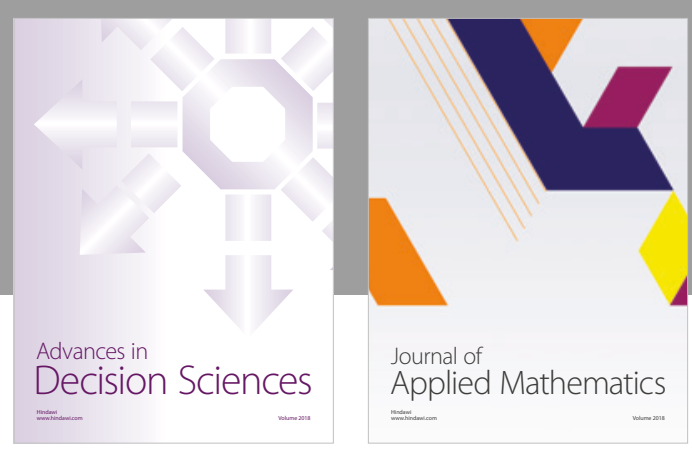

Journal of

Applied Mathematics
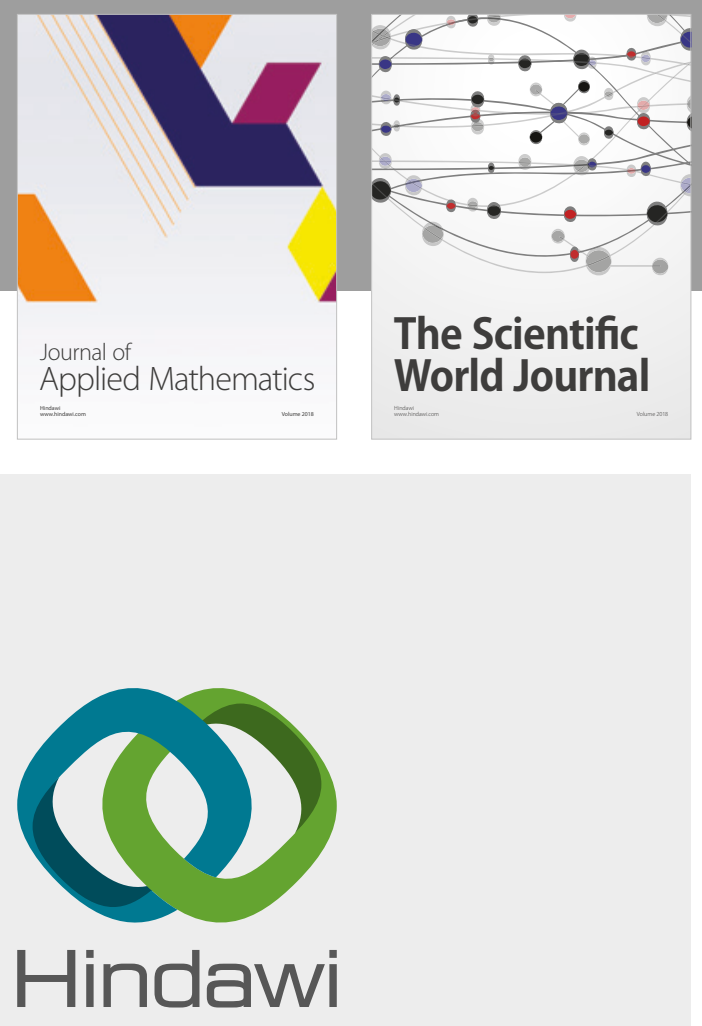

Submit your manuscripts at

www.hindawi.com

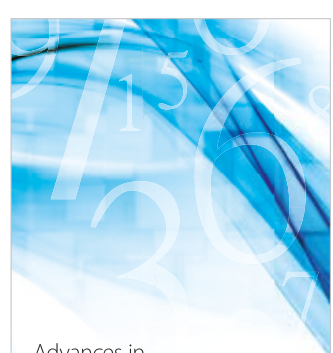

Advances in
Numerical Analysis
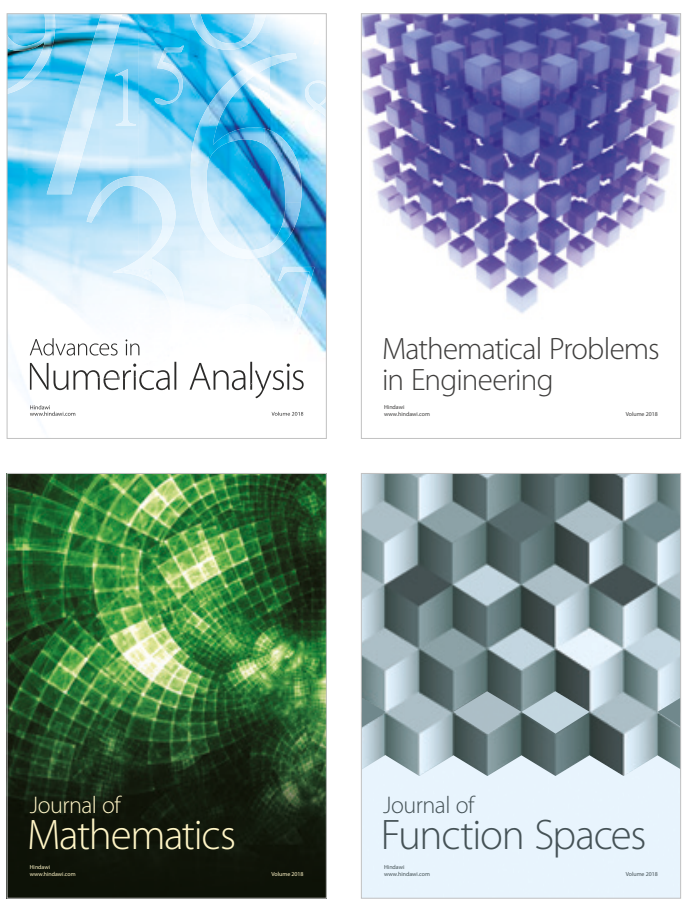

Mathematical Problems in Engineering

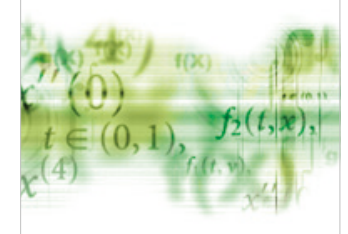

International Journal of

Differential Equations

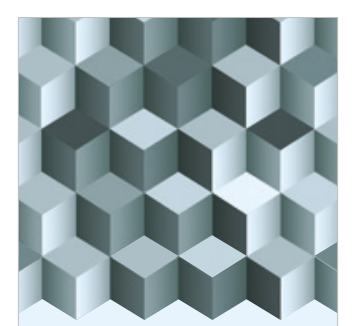

Journal of

Function Spaces

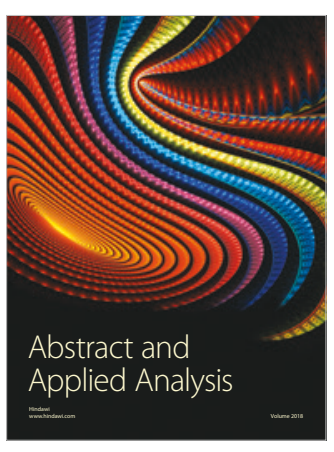

The Scientific

World Journal

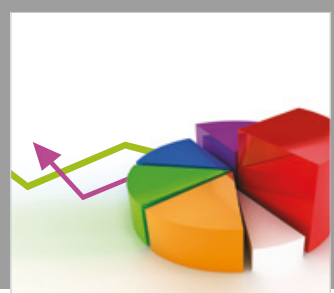

Journal of

Probability and Statistics
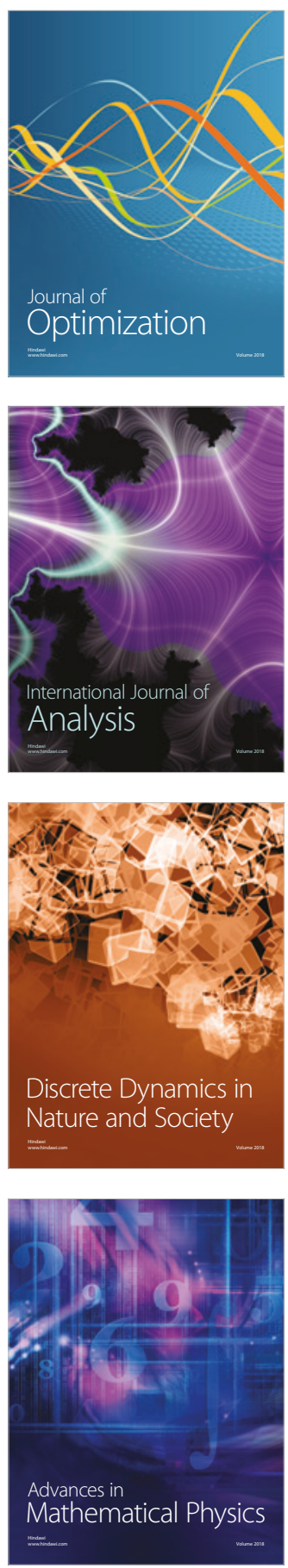